\title{
Dalhousie University School of Social Work Community Clinic: A Space for Innovative Teaching, Learning and Service Delivery
}

\author{
Jeff Karabanow and Cyndi Hall \\ Dalhousie University
}

\begin{abstract}
The Dalhousie University Social Work Community Clinic, a unique inter-professional communityuniversity initiative, opened its doors in 2014 and has supported over 400 marginalized community members and provided field placements for over 65 health profession students. The clinic espouses a social justice/ anti-oppressive teaching, learning and service delivery platform.
\end{abstract}

Keywords: inter-professional clinic, social work clinic, health professional student training, anti-oppressive service delivery, social justice organization

\section{RÉSUMÉ}

Inaugurée en 2014, la clinique communautaire de l'École de service social de l'Université Dalhousie est une initiative interprofessionnelle unique qui réunit la communauté et l'université. Depuis son ouverture, la clinique a épaulé plus de 400 membres marginalisés de la communauté et favorisé l'accès à des stages pratiques de formation à plus de 65 étudiants du domaine de la santé. La clinique adhère à une plateforme d'enseignement, d'apprentissage et de prestation de services reposant sur les valeurs de justice sociale, anti-oppressives.

Mots clés : clinique interprofessionnelle; clinique de travail social, formation d'étudiants du domaine de la santé, prestation de services anti-oppressifs, organisation vouée à la justice sociale

Jeff Karabanow, School of Social Work, Dalhousie University, Halifax, NS; Cyndi Hall, School of Social Work, Dalhousie University, Halifax, NS.

Correspondence concerning this article should be addressed to Jeff Karabanow, Professor, School of Social Work, Dalhousie University, Halifax, Nova Scotia. Email: jkaraban@dal.ca 
The Dalhousie University School of Social Work, through the work of Dr. Jeff Karabanow, full professor, and Ms. Cyndi Hall, field education coordinator, has developed a unique and creative inter-professional teaching, learning, and service delivery initiative called the Dalhousie Social Work Community Clinic situated in the north end of Halifax. Our funds have come from the university's president's office, the Faculty of Health Professions, the School of Social Work, NS Department of Community Services, NS Department of Labour and Advanced Education and NS Department of Health and Wellness, and some small community fundraising efforts.

The clinic employs an anti-oppressive/social justice case management and supportive counselling platform (Ramsundarsingh \& Shier, 2017) to support individuals and families who are marginalized, alienated, and living in poverty. The vast majority are suffering from physical/mental health concerns. The clinic is coordinated and supervised by graduates from our school, and not only attempts to complement and supplement existing resources in the Halifax Region Municipality, but also acts as a training ground for health professional students as a field placement option. The Dalhousie Community Clinic includes the strategic interests of student engagement and experiential learning by providing alternative interprofessional educational opportunities for Dalhousie students to engage in the community while meeting the needs of their academic program.

This initiative has three major objectives, including alternative inter-professional field placement and internship opportunities for Dalhousie students, building an important bridge between Dalhousie University and the Halifax community, and providing meaningful case management and counselling supports for those living in poverty and experiencing mental/physical health issues. The Dalhousie School of Social Work Community Clinic engages students in a placement site that provides learning opportunities within an interprofessional community-based setting/clinic that is rooted within an anti-oppressive practice framework. This program attempts to support and enhance existing connections between Dalhousie University and the Halifax community by building partnerships and allies with community members and service-delivery agencies while working in collaboration to try to fill the gaps of support and provide essential services to Halifax's most marginalized individuals. At the same time, this program works to eliminate some of the responsibility placed on the currently operating programs by minimizing waitlists and fostering communication and cooperative case management between agencies through informed consent and release of information protocols. Lastly our clinic can respond to the ever-increasing demand and competition for quality field placement sites (due to increased student numbers and programs offering practicums).

\section{COMMUNITY PARTNERSHIPS AND ENGAGEMENT}

Over four years of operation, the clinic has built deep and lasting partnerships with more than 35 service delivery organizations in the community. The clinic continues to spend a significant amount of time engaging in community development and knowledge mobilization/translation in order to build the foundation of these partnerships. The clinic receives referrals from a wide range of sources including Immigrant Settlement and Integration Services, Dalhousie Legal Aid, Capital Health Addictions and Mental Health Program, Family SOS, Department of Justice, the Department of Community Services, Salvation Army, St. Mary's Drop-in Centre, the Halifax Infirmary, and QEII Emergency Services. Additionally, the clinic has 
also engaged in social justice-oriented work through supporting other community advocacy organizations as well as sitting on a diversity of external committees and participating in local working groups. The services offered by the clinic are becoming more and more essential as we witnessed a loss of funding and services in other community agencies.

\section{SERVICES}

Rooted in the accompaniment/"walking with" approach to practice (Watkins, 2015), this program serves as a resource centre for marginalized individuals who may not fit into traditional support settings or those who are not yet connected to the already existing network of social service agencies in Halifax. We have supported clients with physical and/or mental health concerns through a case management model incorporating system navigation, needs assessments, advocacy, brokering, facilitation, case planning, case conferencing, supportive counselling, outreach, and crisis management. Research has demonstrated that there is a need for community navigators, especially in many of the populations we work with, who can connect clients to mental health and addictions services as well as assisting clients in the continuing process of facilitating and coordinating other services (Karabanow et al., 2018). While clients were not engaged in the planning/ development/implementation processes of this initiative, we are deeply client-centred and remain a safe space for whatever services they might need.

\section{CLIENTS}

The Community Clinic has officially been in operation and providing services since June 1, 2014. Since that time there have been more than 400 referrals to the clinic. Individuals coming into the clinic are seeking services around a wide range of needs and issues. Often the individuals to whom we are providing services have complex physical and mental health needs with very few existing supports. Individuals seeking services from the clinic have primarily been looking for support, resources, navigation, and advocacy concerning housing; tenancy issues (e.g., eviction prevention); Department of Community Services (e.g., income assistance, child protection, and services for persons with disabilities); healthcare; mental health and substance use related issues; loss of identification; English additional language (ESL/EAL) programs; employment support; family-related issues; and emergency needs (e.g., food, clothing, furniture, shelter, etc.). The clinic has successfully been able to support clients with need for all of these issues through engaging in work both at the clinic and in the community.

\section{STUDENT ENGAGEMENT}

Essential to the clinic's mandate is student learning and engagement. The clinic has provided interprofessional practice experiences to approximately 65 undergraduate and graduate students from social work, occupational therapy, nutrition, psychology, and pharmacy, as well as project-based and service learning opportunities for medicine and management programs at Dalhousie University. Students from a diversity of programs can work collaboratively under the supervision of clinic social work coordinators to provide comprehensive supports to those experiencing poverty and marginalization. Supervision is done through regular team meetings and we have had two informal evaluations completed by graduate students as part of 
theses or research projects. The clinic allows a space for students to participate in grassroots, communitybased learning, where they can solidify connections between theory and practice. Plans are underway to include nurse practitioner students and we are strengthening our learning objectives for inter-professional collaborative practice development. We are pleased to be able to provide students with practicums that offer inter-professional learning opportunities within a community-based setting that is rooted in an anti-oppressive practice framework.

\section{CONCLUSION}

We have much to celebrate with this initiative-its community development roots, its social justice framework, its anti-oppressive emblems and its accompaniment philosophy. While indeed a work in progress, the clinic signals a social work initiative that can embrace an inter-professional lens, be a bridge between the worlds of community and university, focus upon meeting the needs of our marginalized communities, and provide thoughtful and meaningful training grounds for emerging health professionals. Our model supports other social agencies as we do not have a specific mandate and can assist with gaps in both formal and informal social systems. Having access to a variety of health professionals without financial cost and in a timely fashion strengthens the entire community. We are very much focused on the social determinants of health and what the client is presenting as their primary needs.

There are constraints as well, of course. We continue to seek consistent and sustainable funding in order to maintain the clinic's operations and eventually expand to newer offerings (e.g., drop in, therapeutic supports). Moreover, we are continually working to balance our service delivery platform with true community development and advocacy orientations of anti-oppressive practices. We hope to maintain our social justice lens and work with our communities to advocate for a more just and equitable society. We are diligent in our efforts to maintain our unique philosophy and offer transformative learning opportunities for students.

\section{REFERENCES}

Karabanow, J., Kidd, S, Frederick, T. \& Hughes, J. (2018). Homeless youth and the search for stability. Waterloo: Wilfrid Laurier University Press.

Ramsundarsingh, S., \& Shier, M. L. (2017). Anti-oppressive organisational dynamics in the social services: A literature review. British Journal of Social Work 47(8), 2308-2327.

Watkins, M. (2015). Psychosocial accompaniment. Journal of Social and Political Psychology, 3(1), 324-341. 